\title{
Grant scores leave applicants in limbo
}

Applicants for the coveted Challenge Grants issued by the US National Institutes of Health (NIH) as part of the American Recovery and Reinvestment Act learned the peer-review scores for their proposals late last month. Yet they received little in the way of certainty over whether those scores will translate into money come September, when the NIH will announce which grants it plans to fund.

Competition for the US\$1-million, two-year awards is fierce - the agency in Bethesda, Maryland, received more than 21,000 applications, and the NIH director's office will fund only about $1 \%$ of these.

"I don't think I've ever been

\section{"I don't think I've ever been ambivalent} about a second percentile score."

With ordinary grants, applicants can usually tell if their grant is fundable as soon they receive their percentile score because they already know the designated 'payline', or percentage of fundable applications. The NIH has designated an initial $\$ 200$ million of $\$ 10.4$ billion in economic stimulus funds for the grants, but with so many variables at play in allocating the stimulus money, predicting whether a given score will land funding is almost impossible - meaning that those with percentile scores in the mid-single digits are left hanging.

For example, Paul Janssen, a cardiac physiologist at Ohio State University in Columbus, scored ambivalent about a second percentile score" that would normally be assured funding, says Joe Hogan, a biostatistician at Brown University in Providence, Rhode Island, who hopes to use a Challenge Grant to study behavioural interventions for reducing alcohol abuse. a sixth percentile on his 'infrastructure' application, which, if funded, would build a system for obtaining and testing live tissue from healthy and failing human hearts. "I am cautiously optimistic," he says, only because the institute sponsoring the grant - the National Heart, Lung and
Blood Institute - is planning to go beyond the allocation from the director's office and fund 200 Challenge Grants in its topic areas. Some of the 27 institutes within the NIH are less enthusiastic about funding extra Challenge Grants and have chosen to use stimulus funds in other ways - for example, to boost existing investigatorinitiated grants, or to sponsor standard grants that had fallen just short of the payline before the stimulus windfall arrived.

Meanwhile, the burden on the thousands of grant reviewers has, according to some, turned out to be bearable. Gary Johnson, chairman of the pharmacology department at the University of North Carolina, Chapel Hill, told the $\mathrm{NIH}$ that he could review up to five Challenge Grant applications. "And they only gave me a couple," he says. "I don't know anyone who was overwhelmed by reviewing, because there was an overwhelming agreement of investigators to participate in the process."

Meredith Wadman 